\title{
Predicting medical complications in spine surgery: evaluation of a novel online risk calculator
}

\author{
Maximilian F. Kasparek ${ }^{1}$ - Friedrich Boettner ${ }^{2}$ - Anna Rienmueller ${ }^{1} \cdot$ Michael Weber $^{3}$. Philipp T. Funovics ${ }^{1}$. \\ Petra Krepler ${ }^{1} \cdot$ Reinhard Windhager $^{1} \cdot$ Josef Grohs ${ }^{1}$
}

Received: 16 September 2017 / Revised: 16 July 2018 / Accepted: 16 July 2018 / Published online: 28 July 2018

(c) The Author(s) 2018

\begin{abstract}
Purpose The preoperative prediction of medical complications is essential to optimize perioperative management. SpineSage $^{\mathrm{TM}}$ is a free of charge online calculator to predict medical complications in spine surgery. The current study utilizes it in patients undergoing spine surgery to assess whether the predicted risks would correlate with the actual complication rate in clinical practice.

Methods A total of 273 consecutive patients who underwent spinal surgery were assessed. The risk of medical complications was predicted for each patient, and all medical complications were recorded within 30 days of surgery. Based on their predicted risk of complication, patients were divided into three risk groups $(<15,15-30,>30 \%)$.

Results The predicted overall risk of medical complications was $14.7 \%$ and was comparable to the observed complication rate of $16.1 \%$. The predicted risk for major medical complications (3.8\%) was also similar to the observed complication rate (3.3\%). Detailed analysis of the segmented risk groups suggests a close correlation between predicted and actual complication rates. Receiver operating characteristic analysis revealed an area under the curve of $0.71(p<0.001)$ for the prediction of overall medical complications and $0.85(p<0.001)$ for major complications.

Conclusions The online risk calculator predicted both overall and major medical complications. The tool can assist in preoperative planning and counseling of patients.
\end{abstract}

Graphical abstract These slides can be retrieved under Electronic Supplementary Material.
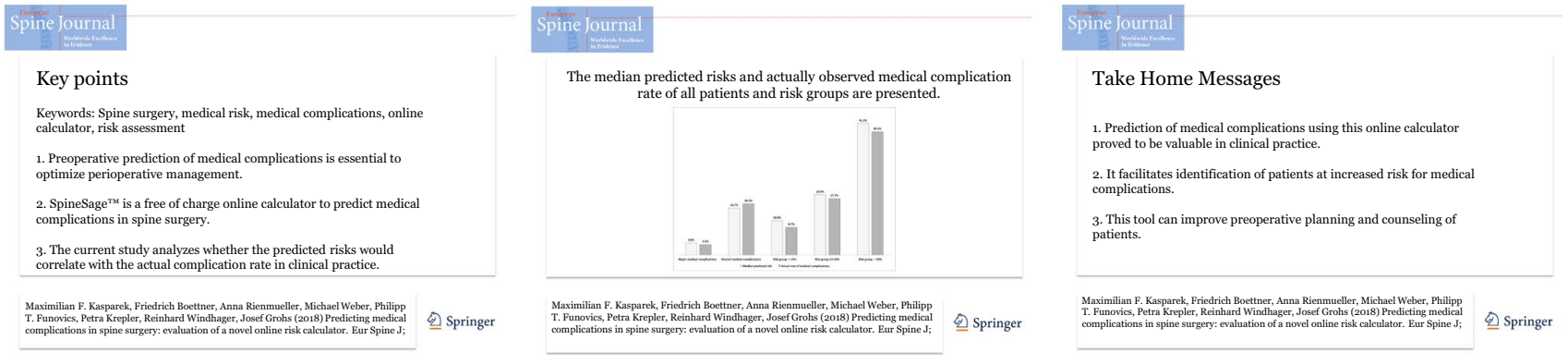

Keywords Spine surgery $\cdot$ Medical risk $\cdot$ Medical complications $\cdot$ Online calculator $\cdot$ Risk assessment

Electronic supplementary material The online version of this article (https://doi.org/10.1007/s00586-018-5707-9) contains supplementary material, which is available to authorized users.

Josef Grohs

josef.grohs@meduniwien.ac.at

Extended author information available on the last page of the article

\section{Introduction}

Since bundled payment programs often include the reimbursement for complication and readmission, it has become increasingly important to identify patients at risk for perioperative complications [1-4]. 
Being able to identify patients at risk for medical and surgical complications helps to better prepare the patient for the procedure based on patient-specific risk factors and invasiveness of the procedure and ultimately might help to reduce the overall complication rate. In the past, several significant risk factors for medical complications in spine surgery were identified utilizing multivariate analysis [5-7]. However, a risk stratification tool that is easy to integrate into clinical practice has been missing.

Lee et al. [8] created a validated model for predicting medical complications after spine surgery based on a prospective spine surgery registry. It is meant to simplify preoperative assessment by taking into consideration patient-specific risk factors as well as the invasiveness of the procedure (Fig. 1).

This risk calculator is available online free of charge. It allows the surgeon to calculate the risk for perioperative medical complication for a specific patient and procedure [8]. There are currently no data available that analyze the clinical value of this perioperative risk calculator.

The current study reports the initial clinical experience with this risk assessment tool and analyzes the following research questions: (1) Is there a difference between the predicted overall medical complication rate and the observed complication rate? (2) What is the value of the tool for patients with different risk levels? (3) Furthermore, does the tool have a diagnostic value for the prediction of complication?

\section{Materials and methods}

The current study evaluates 273 consecutive patients, who underwent one-stage spinal surgery in a tertiary care center. The study was approved by the institutional review board. All medical complications in the first 30 postoperative days were recorded. Medical complications were divided into six main organ systems (cardiac, pulmonary, gastrointestinal, neurologic, hematologic and urologic) as previously reported by Lee et al. [8]. Furthermore, in this classification system, complications were grouped into overall and major complications. Complications with a significant impact on the patients' recovery, e.g., myocardial infarction, cerebrovascular accidents (CVA/TIA) or pulmonary embolism were considered major medical complications. All other medical complications (e.g., cardiac arrhythmia, pneumonia and deep vein thrombosis) were considered overall medical complications. However, surgical complications (dural tear, iatrogenic nerve injury or hardware failure) were not considered. Detailed information was published by Lee et al. [8].

The risk of medical complications for each patient according to his/her comorbidity profile and planned surgical invasiveness was estimated online using the freely available risk calculator (SpineSage ${ }^{\mathrm{TM}}$ ) [8]. It provides likelihood values in absolute percentages for occurrence of a complication for an individual patient, based on the patients comorbidity profile and planned surgical invasiveness. Estimated risks of SpineSage ${ }^{\mathrm{TM}}$ were not used to make changes in the operative decision making process as it is not an approved medical product. SpineSage ${ }^{\mathrm{TM}}$ utilizes preexisting comorbidities, like hypertension, congestive heart failure or diabetes as well as
Fig. 1 The 3D model is showing that risk depends on two factors: patients' comorbidity profile and invasiveness of surgery. Risk increases either through an increased amount of preexisting medical conditions or due to more invasiveness surgery. SpineSage ${ }^{\mathrm{TM}}$ is the first predictive model that connects either factors and predicts an individual patient risk

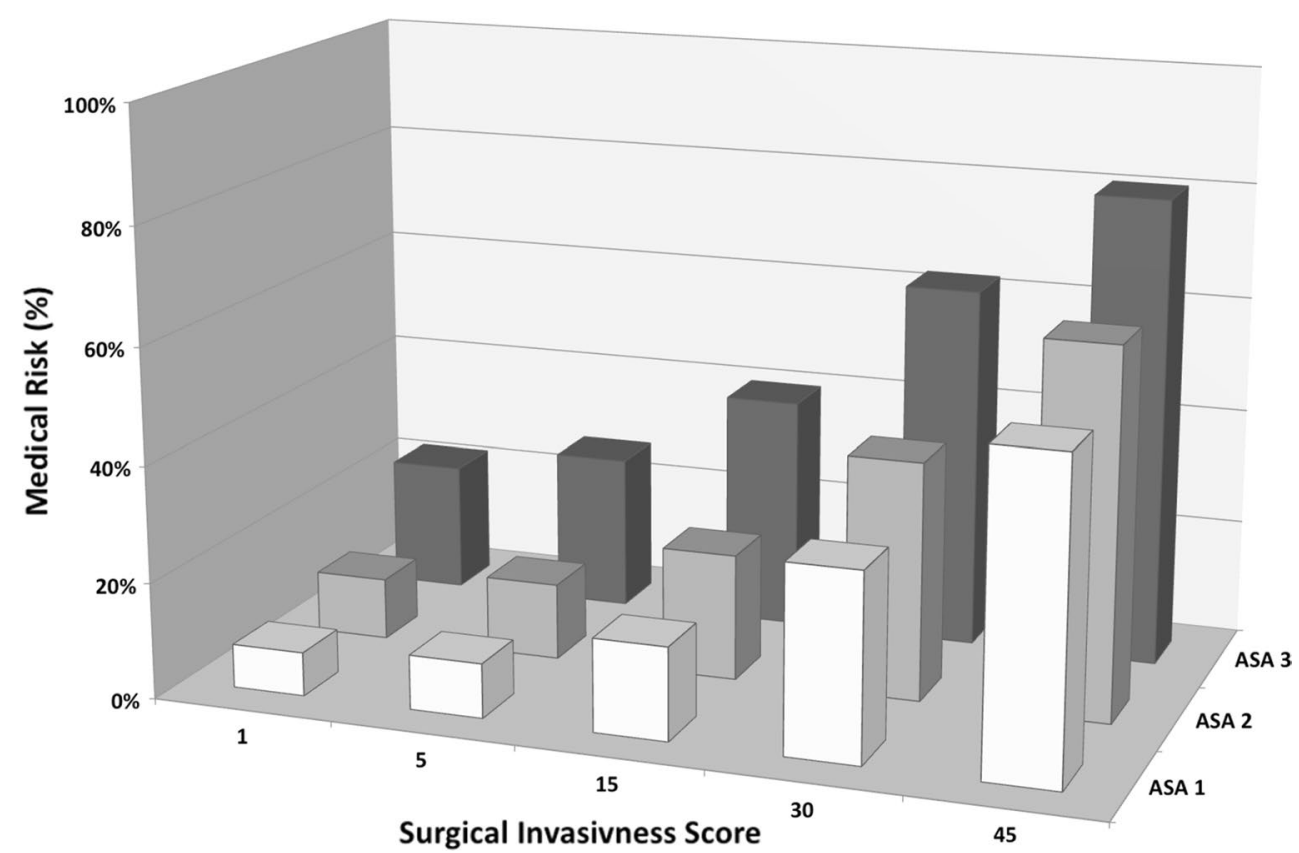


age, gender and BMI to calculate the patient-specific risk. It also considers a history of previous spine surgery (history of any prior spinal surgery at any segment) and revision surgery (surgical-related complications to a prior surgery, e.g., hardware failure).

Surgical invasiveness is graded based on the surgical invasiveness index (SII), which was described by Mirza et al. [9]. The index considers the number of levels that are decompressed, fused or instrumented as well as the approach (posterior vs. anterior). A higher SII score indicates increased surgical invasiveness accompanied by higher blood loss and longer surgical time. Given all these informations, SpineSage ${ }^{\mathrm{TM}}$ then predicts for a patient the risk for overall medical complications and major medical complications.

Preoperative assessment also included the Charlson comorbidity index (CCI) [10] and the American Society of Anesthesiologists (ASA) score. For statistical analysis, Pearson's Chi-square test was used to compare median preoperative predicted risks with the actually occurred complication rate. For assessment of the diagnostic value of the calculator, a receiver operator characteristics (ROC) analysis to determine the area under the curve (AUC) was obtained from the predictions of the risk calculator and actually recorded medical complications. An AUC of $>0.8$ was considered as a good clinical test and an AUC of $>0.7$ as a fair clinical test [11]. A $p$ value of $<0.05$ was considered as statistically significant. All statistical analyses were performed using SPSS software (version 23.0 for Mac; SPSS, Chicago, ILL).

\section{Results}

The mean patients' age was 61 years (range 18-87 years), and mean BMI was $27.0 \mathrm{~kg} / \mathrm{m}^{2}$ (range $17-45 \mathrm{~kg} / \mathrm{m}^{2}$ ). The CCI median was 3 points (range $0-13$ points), and patients had a median of 2 comorbidities (range $0-8$ ). At the time of surgery, 33 patients were classified as ASA I (12.1\%), 152 patients were classified as ASA II (55.7\%), followed by 81 patients as ASA III (29.7\%) and 7 patients as ASA IV (2.5\%). Hypertension and previous spinal surgery were the most common preexisting medical risk factors. Most surgical interventions were performed for degenerative spine conditions (226 patients $(82.8 \%)$ ), followed by 26 patients operated on for neoplasm (9.5\%), 10 patients for trauma (3.7\%) and 11 patients for infection (4\%). The location of surgery was lumbosacral in 215 patients $(78.8 \%)$, cervical in 34 patients $(12.4 \%)$ and thoracic in 24 patients $(8.8 \%)$. The most common approach was the posterior approach (252 patients $(92.3 \%)$ ), followed by the anterior approach (17 patients $(6.2 \%))$ and only 4 patients $(1.5 \%)$ underwent a combined anterior-posterior approach. Furthermore, cases were separated into three risk groups regarding their predicted overall medical risk $(<15,15-30,>30 \%)$. Detailed demographics of all groups are presented in Table 1. Values are expressed as mean/median with range or $95 \%$ confidence intervals $(95 \% \mathrm{CI})$. For the total sample size $(n=273)$ of the current study, the $95 \%$ confidence interval is within plus/ minus $4.6 \%$.

The predicted median overall medical complication rate was $14.7 \%$ (range $3.3-89.2 \%$ ), and the actually observed complication rate was $16.1 \%$ (44 patients). Pulmonary complications occurred in 16 patients (26.2\%), followed by neurological complications in 11 patients $(18.0 \%)$ and cardiac complications in 10 patients (16.4\%). Less common were gastrointestinal complications and urological complications, both in 9 patients (14.8\%), and hematologic complications, in 6 patients $(9.8 \%)$. In total, 61 medical complications were documented in 44 patients.

The median predicted major complication risk was 3.8\% (range 0.5-63.8\%), and 3.3\% (9 patients) of the patients had a major medical complication (Tables 2, 3). Two patients died, a myocardial infarction occurred in one patient, with a predicted overall medical risk of $26.3 \%$ and major medical risk of $11.2 \%$. The second patient, with a predicted overall medical risk of $41.2 \%$ and major risk of $5.7 \%$, had a mesenterial infarction. There was no difference in the predicted and observed major medical complication rate $(p=0.515)$ as well as in the overall medical complication rate $(p=0.693)$ (Table 2; Fig. 2).

Furthermore, analysis of the different risk groups showed in the low-risk group (predicted overall medical complication rate $<15 \%$ ) a median predicted risk of $10.8 \%$. In reality, $8.7 \%$ of the patients in this group suffered a medical complication. In the medium-risk group, defined by a median estimated risk between 15 and 30\%, the median predicted risk was $18.9 \%$ compared to $17.7 \%$ of the patients in this group who actually had a medical complication. In the high-risk group, with a preoperative predicted risk exceeding $30 \%$, the median predicted risk was $41.1 \% .38 .5 \%$ of the patients in this group had an actual medical complication. Difference analysis suggests that the predicted and actually observed medical complication rate was not statistically different $(p>0.05)$ (Table 2; Fig. 2).

Clinical value of the risk prediction calculator was assessed using ROC analysis. The AUC for prediction of overall medical complications was $0.71(p<0.001)$ and for major complications $0.85(p<0.001)$ (Table 4; Figs. 3, 4).

\section{Discussion}

The combination of improvements in surgical techniques, extending surgical indications and an aging society with increasing medical comorbidities makes preoperative risk screening tools increasingly important to guide patients in the preoperative decision for surgery. SpineSage ${ }^{\mathrm{TM}}$ appears 
Table 1 Patient demographics of all patients are presented

\begin{tabular}{lllll}
\hline & Risk $<15 \%$ & Risk 15-30\% & Risk>30\% & Total \\
\hline Patients & 138 & 96 & 39 & 273 \\
Female/male & $81 / 57$ & $59 / 46$ & $23 / 16$ & $159 / 114$ \\
Age $^{\mathrm{a}}$ & $53(18-75)$ & $66(18-87)$ & $74(45-87)$ & $61(18-87)$ \\
${\text { BMI }\left(\mathrm{kg} / \mathrm{m}^{2}\right)^{\mathrm{a}}}^{\mathrm{CCI}}{ }^{\mathrm{b}}$ & $26.7(17-45)$ & $27.2(18-40)$ & $27.0(18-38)$ & $27.0(17-45)$ \\
Preexisting conditions $^{\mathrm{b}}$ & $2(0-10)$ & $3(0-11)$ & $5(0-13)$ & $3(0-13)$ \\
SII $^{\mathrm{b}}$ & $1(0-6)$ & $2(0-5)$ & $4(0-7)$ & $2(0-7)$ \\
ASA I & $3(1-18)$ & $8(1-31)$ & $10(1-30)$ & $8(1-31)$ \\
ASA II & $21.7 \%(30)$ & $3.1 \%(3)$ & - & $12.1 \%(33)$ \\
ASA III & $64.5 \%(89)$ & $55.2 \%(53)$ & $25.6 \%(10)$ & $55.7 \%(152)$ \\
ASA IV & $13.1 \%(18)$ & $38.6 \%(37)$ & $66.7 \%(26)$ & $29.7 \%(81)$ \\
Degenerative & $0.7 \%(1)$ & $3.1 \%(3)$ & $7.7 \%(3)$ & $2.5 \%(7)$ \\
Trauma & $90.6 \%(125)$ & $84.4 \%(81)$ & $51.3 \%(20)$ & $82.8 \%(226)$ \\
Neoplasm & - & $1.0 \%(1)$ & $23.1 \%(9)$ & $3.7 \%(10)$ \\
Infection & $9.4 \%(13)$ & $10.4 \%(10)$ & $7.7 \%(3)$ & $9.5 \%(26)$ \\
Cervical & - & $4.2 \%(4)$ & $17.9 \%(79)$ & $4.0 \%(11)$ \\
Thoracic & $14.5 \%(20)$ & $9.4 \%(9)$ & $12.8 \%(5)$ & $12.4 \%(34)$ \\
Lumbosacral & $6.5 \%(9)$ & $8.3 \%(8)$ & $18.0 \%(7)$ & $8.8 \%(24)$ \\
Anterior & $79.0 \%(109)$ & $83.3 \%(79)$ & $69.2 \%(27)$ & $78.8 \%(215)$ \\
Posterior & $11.6 \%(16)$ & $1.0 \%(1)$ & - & $6.2 \%(17)$ \\
Combined & $87.7 \%(121)$ & $95.9 \%(92)$ & $100 \%(39)$ & $92.3 \%(252)$ \\
\hline & $0.7 \%(1)$ & $3.1 \%(3)$ & - & $1.5 \%(4)$ \\
\hline
\end{tabular}

Moreover, patients were divided into three risk groups according to their predicted overall medical risk

$B M I$ body mass index, $C C I$ Charlson comorbidity index, ASA American Society of Anesthesiologists and SII surgical invasiveness index

${ }^{\mathrm{a}}$ Mean

${ }^{\mathrm{b}}$ Median

Table 2 Median predicted risks and actual rate of occurred medical complications of all patients and all risk groups are shown

\begin{tabular}{|c|c|c|c|c|c|}
\hline & $\begin{array}{l}\text { Major medical complica- } \\
\text { tions }\end{array}$ & $\begin{array}{l}\text { Overall medical compli- } \\
\text { cations }\end{array}$ & Risk group $<15 \%$ & Risk group 15-30\% & Risk group $>30 \%$ \\
\hline $\begin{array}{l}\text { Median predicted risk } \\
\text { (range) }\end{array}$ & $3.8 \%(0.5-63.8 \%)$ & $14.7 \%(3.3-89.2 \%)$ & $10.8 \%(2.7-14.9 \%)$ & $18.9 \%(15.1-29.7 \%)$ & $41.1 \%(30.4-89.2 \%)$ \\
\hline $\begin{array}{l}\text { Actual rate of occurred } \\
\text { medical complications } \\
(95 \% \text { CI })\end{array}$ & $\begin{array}{l}3.3 \%(n=9)(95 \% \mathrm{CI} \\
\quad 1.7-6.1)\end{array}$ & $\begin{array}{l}16.1 \%(n=44)(95 \% \mathrm{CI} \\
12.2-20.9)\end{array}$ & $\begin{array}{l}8.7 \%(n=12)(95 \% \\
\quad \text { CI } 5.0-14.6)\end{array}$ & $\begin{array}{l}17.7 \%(n=17)(95 \% \\
\text { CI 11.4-26.5) }\end{array}$ & $\begin{array}{l}38.5 \%(n=15)(95 \% \\
\quad \text { CI } 24.9-54.1)\end{array}$ \\
\hline$p$ value & 0.515 & 0.693 & 0.418 & 0.767 & 0.731 \\
\hline
\end{tabular}

Medical complications with a significant impact on the patients' recovery, e.g., myocardial infarction, cerebrovascular accidents (CVA/TIA) or pulmonary embolism were considered major medical complications. All other medical complications (e.g., cardiac arrhythmia, pneumonia and deep vein thrombosis) were considered overall medical complications

to be clinically useful in predicting the overall medical complication rate as well as major medical complication rate following spine surgery.

The current study has the following limitations: (1) Patients were operated in a tertiary care center, and the results might be different in a lower-level care center. (2) The current study analyzes a limited number of patients and might be underpowered. (3) The authors included only the 30 days complication rate and might underestimate overall complication rates. However, the American College of
Surgeons National Surgical Quality Improvement Program (ACS-NSQIP) also utilizes a 30-day complication rate. The calculation of complications in this time period is of main interest, as bundled payment programs include costs for complications and readmissions within 30 days. (4) The study enrolled all patients who were admitted to the author's institution, which resulted in a mixed patient population of degenerative, neoplasm and infection cases. In contrast, Karstensen et al. [12] and Yadla et al. [13] included similar patient groups to report medical complications. 
Table 3 Detailed information of patients who occurred a major medical complication is presented

\begin{tabular}{lllllllllll}
\hline Gender & Age & Diagnosis & Level & BMI & CCI $\begin{array}{l}\text { Preexisting } \\
\text { conditions }\end{array}$ & SII & $\begin{array}{l}\text { ASA } \\
\text { Risk major } \\
\text { complications } \\
(\%)\end{array}$ & $\begin{array}{l}\text { Risk overall } \\
\text { complications } \\
(\%)\end{array}$ \\
\hline F & 73 & N & C & 23.5 & 10 & 3 & 12 & 4 & 5.5 & 22.1 \\
F & 74 & D & L & 23.9 & 6 & 3 & 12 & 3 & 5.7 & 41.2 \\
M & 45 & D & L & 37.1 & 0 & 0 & 30 & 2 & 7.1 & 32.3 \\
M & 60 & D & L & 30.1 & 3 & 2 & 14 & 2 & 7.7 & 21.8 \\
F & 75 & D & L & 35.5 & 3 & 1 & 12 & 3 & 9.1 & 23.0 \\
M & 82 & N & L & 29.4 & 10 & 1 & 12 & 3 & 11.2 & 26.3 \\
M & 74 & D & T & 28.9 & 3 & 2 & 28 & 3 & 19.7 & 42.2 \\
F & 77 & I & T & 24.5 & 4 & 2 & 10 & 3 & 28.6 & 48.6 \\
M & 75 & T & T & 36.7 & 5 & 6 & 15 & 3 & 63.8 & 89.2 \\
\hline
\end{tabular}

$F$ female, $M$ male, $N$ neoplasm, $D$ degenerative, $I$ infection, $T$ trauma, $C$ cervical, $T$ thoracic, $L$ lumbosacral, CCI Charlson comorbidity index, SII surgical invasiveness index, ASA American Society of Anesthesiologists

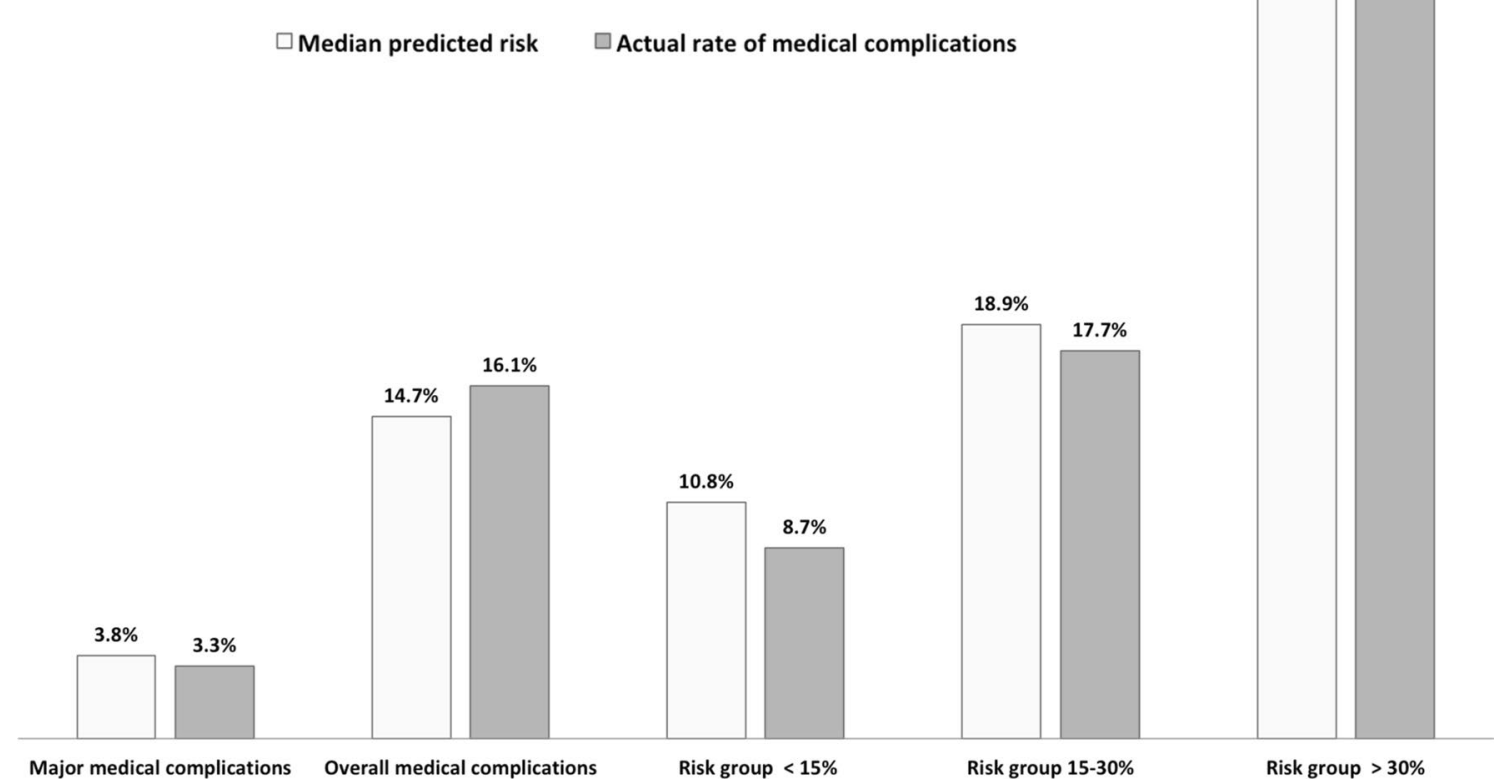

Fig. 2 The median predicted risks and actually observed medical complication rate of all patients and risk groups are presented

Table 4 The diagnostic values of the online calculator for predicting major and overall medical complications are presented

\begin{tabular}{lll}
\hline & $\begin{array}{l}\text { Major medical complica- } \\
\text { tions }\end{array}$ & $\begin{array}{l}\text { All medical compli- } \\
\text { cations }\end{array}$ \\
\hline AUC (95\% CI) & 0.71 (95\% CI 0.63-0.80) & $\begin{array}{c}0.85(95 \% \text { CI } \\
0.773-0.929)\end{array}$ \\
$p$ value & $<0.001$ & $<0.001$ \\
\hline
\end{tabular}

$A U C$ area under the curve
In the past decade, preoperative risk stratification and individual patient counseling have become of increasing importance in spine surgery. It is well known that perioperative complications are associated with prolonged hospital stays and inferior clinical outcome [14, 15]. Furthermore, it was recently reported by Su et al. [16] that the preoperative identification of high-risk patients and planned targeted modifications of risk factors might help to prevent 


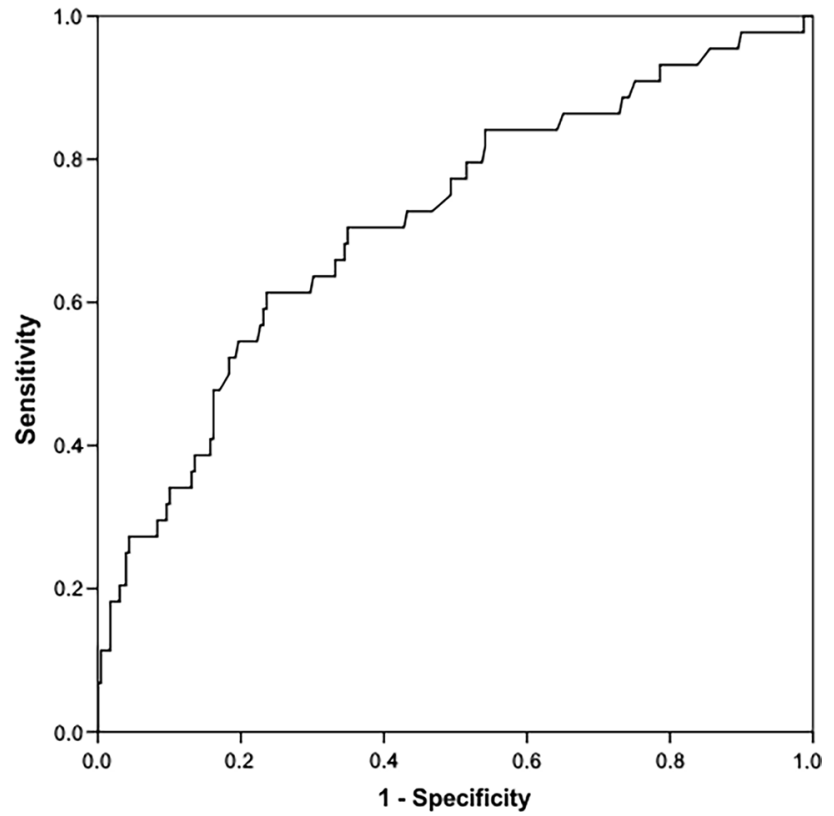

Fig. 3 Receiver operator characteristic curve for the prediction of any medical complication

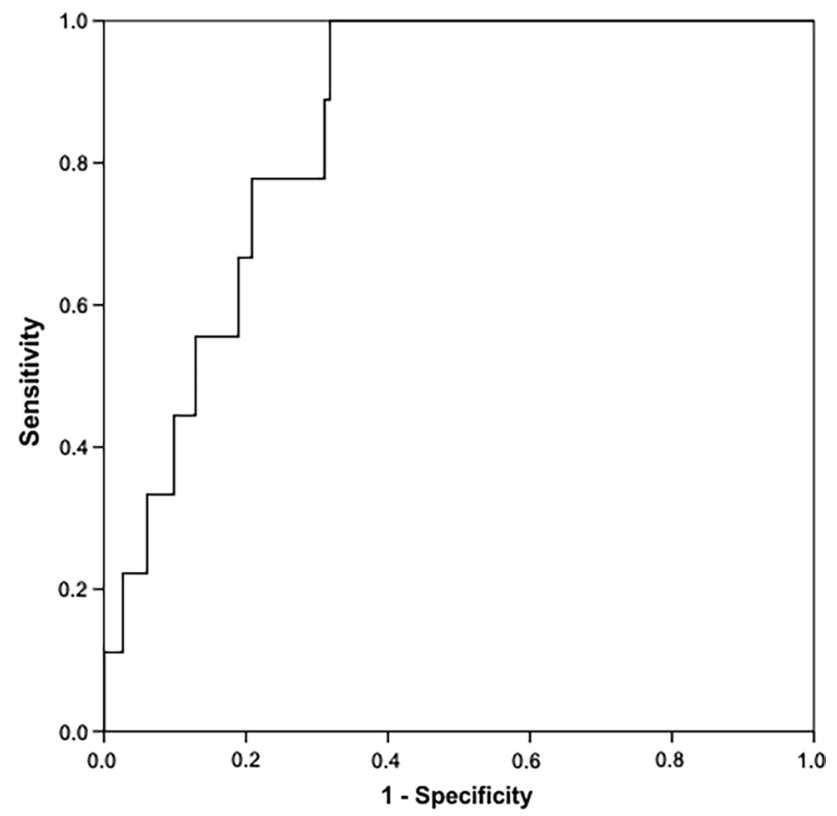

Fig. 4 Receiver operator characteristic curve for prediction of major complications

complications. Therefore, efforts have been made to develop preoperative risk assessment algorithms. Schoenfeld et al. [1] identified cardiac disease and an ASA score of $>2$ as independent risk factors for medical complications after spine surgery. Mannion et al. [17] reported that an increasing ASA score is associated with a higher incidence of perioperative complications. They concluded that the ASA score might be used in preoperative counseling of patients about their perioperative risk. Moreover, Arrigo et al. [18] identified the Charlson comorbidity index (CCI) as a useful predictive tool for complications following spinal metastasis surgery. Also, Whitmore et al. [19] reported that the ASA score and the CCI were useful tools in the preoperative assessment. However, surgical invasiveness was not considered, and their ability to predict occurrence of complications was limited. Veeravagu et al. [20] evaluated the spinal Risk Assessment Tool (RAT), a tool designed for patients undergoing spine surgery and compared it with the ACS-NSQIP surgical risk calculator and the CCI. The lowest accuracy was reported for the CCI. Although the RAT and the ACS-NSQIP risk calculator provided a comparable AUC, the ACS-NSQIP risk calculator tended to underestimate the occurred complication rate. These findings support the need for customized tools for spine surgery. SpineSage ${ }^{\text {TM }}$ is a tool designed to ease the preoperative decision making process in patients undergoing spine surgery. The assessment is based on the individual patient comorbidity profile and the planned surgical invasiveness. However, to our best knowledge, the current study is the first independent attempt to assess SpineSage ${ }^{\mathrm{TM}}$ in daily clinical practice. Lee et al. [8] who developed SpineSage ${ }^{\mathrm{TM}}$ reported an AUC of 0.76 for the detection of any medical complication and an AUC of 0.81 for major complications, which is quite similar to the data reported in the current study. Lee et al. [8] excluded tumor patients from their statistical analysis but suggested the possibility to assess tumor patients with the online calculator. The current study included patients with tumor diagnosis, and the study showed that SpineSage ${ }^{\mathrm{TM}}$ remains an accurate tool.

Analysis of the three risk groups suggests that preexisting medical conditions and increased invasiveness of the surgery increase the risk of medical complication. SpineSage ${ }^{\mathrm{TM}}$ provided a very accurate risk assessment in all risk groups. The incidence of medical complications and major complications was also comparable to previous reports $[1,12,13]$.

\section{Conclusions}

SpineSage ${ }^{\mathrm{TM}}$ provides accurate predictions of overall medical complication risk as well as major complications risks for patients undergoing spine surgery. By identifying patients at risk, it improves preoperative patient optimization as well as communication of realistic expectations prior to surgery.

Acknowledgements Open access funding provided by Medical University of Vienna. 


\section{Compliance with ethical standards}

Conflict of interest We certify that we have not signed any agreement with commercial interest related to this study, which would in any way limit publication of any and all data generated for the study or to delay publication for any reason.One author reports personal fees from Smith \& Nephew, personal fees from Ortho Development Corporation and personal fees from DePuy, outside the submitted work.One author reports consulting for Boehringer Ingelheim, Stryker, Takeda, Pfizer and DePuy, outside the submitted work.

Open Access This article is distributed under the terms of the Creative Commons Attribution 4.0 International License (http://creativeco mmons.org/licenses/by/4.0/), which permits unrestricted use, distribution, and reproduction in any medium, provided you give appropriate credit to the original author(s) and the source, provide a link to the Creative Commons license, and indicate if changes were made.

\section{References}

1. Schoenfeld AJ, Ochoa LM, Bader JO, Belmont PJ Jr (2011) Risk factors for immediate postoperative complications and mortality following spine surgery: a study of 3475 patients from the National Surgical Quality Improvement Program. J Bone Jt Surg Am 93:1577-1582. https://doi.org/10.2106/jbjs.j.01048

2. Bekelis K, Desai A, Bakhoum SF, Missios S (2014) A predictive model of complications after spine surgery: the National Surgical Quality Improvement Program (NSQIP) 2005-2010. Spine J 14:1247-1255. https://doi.org/10.1016/j.spinee.2013.08.009

3. McCormack RA, Hunter T, Ramos N, Michels R, Hutzler L, Bosco JA (2012) An analysis of causes of readmission after spine surgery. Spine 37:1260-1266. https://doi.org/10.1097/brs.0b013 e318245f561

4. Wang MC, Shivakoti M, Sparapani RA, Guo C, Laud PW, Nattinger AB (2012) Thirty-day readmissions after elective spine surgery for degenerative conditions among US Medicare beneficiaries. Spine J 12:902-911. https://doi.org/10.1016/j.spine e.2012.09.051

5. Lee MJ, Hacquebord J, Varshney A, Cizik AM, Bransford RJ, Bellabarba C, Konodi MA, Chapman J (2011) Risk factors for medical complication after lumbar spine surgery: a multivariate analysis of 767 patients. Spine 36:1801-1806

6. Lee MJ, Konodi MA, Cizik AM, Bransford RJ, Bellabarba C, Chapman JR (2012) Risk factors for medical complication after spine surgery: a multivariate analysis of 1591 patients. Spine J 12:197-206. https://doi.org/10.1016/j.spinee.2011.11.008

7. Lee MJ, Konodi MA, Cizik AM, Weinreich MA, Bransford RJ, Bellabarba C, Chapman J (2013) Risk factors for medical complication after cervical spine surgery: a multivariate analysis of 582 patients. Spine 38:223-228. https://doi.org/10.1097/brs.0b013e318268ffc9

8. Lee MJ, Cizik AM, Hamilton D, Chapman JR (2014) Predicting medical complications after spine surgery: a validated model using a prospective surgical registry. Spine J 14:291-299. https:// doi.org/10.1016/j.spinee.2013.10.043
9. Mirza SK, Deyo RA, Heagerty PJ, Konodi MA, Lee LA, Turner JA, Goodkin R (2008) Development of an index to characterize the "invasiveness" of spine surgery: validation by comparison to blood loss and operative time. Spine 33:2651-2661. https://doi. org/10.1097/brs.0b013e31818dad07 (discussion 2662)

10. Charlson ME, Pompei P, Ales KL, MacKenzie CR (1987) A new method of classifying prognostic comorbidity in longitudinal studies: development and validation. J Chronic Dis 40:373-383

11. Tape TG Interpreting Diagnostic Tests. http://gim.unmc.edu/dxtes ts/Default.htm. Last accessed 31 Mar 2016

12. Karstensen S, Bari T, Gehrchen M, Street J, Dahl B (2016) Morbidity and mortality of complex spine surgery: a prospective cohort study in 679 patients validating the Spine AdVerse Event Severity (SAVES) system in a European population. Spine J 16:146-153. https://doi.org/10.1016/j.spinee.2015.09.051

13. Yadla S, Malone J, Campbell PG, Maltenfort MG, Harrop JS, Sharan AD, Ratliff JK (2010) Early complications in spine surgery and relation to preoperative diagnosis: a single-center prospective study. J Neurosurg Spine 13:360-366. https://doi. org/10.3171/2010.3.spine09806

14. Koller H, Pfanz C, Meier O, Hitzl W, Mayer M, Bullmann V, Schulte TL (2016) Factors influencing radiographic and clinical outcomes in adult scoliosis surgery: a study of 448 European patients. Eur Spine J 25:532-548. https://doi.org/10.1007/s0058 6-015-3898-x

15. Samdani AF, Belin EJ, Bennett JT, Miyanji F, Pahys JM, Shah SA, Newton PO, Betz RR, Cahill PJ, Sponseller PD (2016) Major perioperative complications after spine surgery in patients with cerebral palsy: assessment of risk factors. Eur Spine J 25:795800. https://doi.org/10.1007/s00586-015-4054-3

16. Su AW, Habermann EB, Thomsen KM, Milbrandt TA, Nassr A, Larson AN (2016) Risk factors for 30-day unplanned readmission and major perioperative complications following spine fusion surgery in adults: a review of the National Surgical Quality Improvement Program (NSQIP) Database. Spine. https://doi.org/10.1097/ brs. 0000000000001558

17. Mannion AF, Fekete TF, Porchet F, Haschtmann D, Jeszenszky D, Kleinstuck FS (2014) The influence of comorbidity on the risks and benefits of spine surgery for degenerative lumbar disorders. Eur Spine J 23(Suppl 1):S66-S71. https://doi.org/10.1007/s0058 6-014-3189-y

18. Arrigo RT, Kalanithi P, Cheng I, Alamin T, Carragee EJ, Mindea SA, Boakye M, Park J (2011) Charlson score is a robust predictor of 30-day complications following spinal metastasis surgery. Spine 36:E1274-E1280. https://doi.org/10.1097/brs.0b013e3182 $06 \mathrm{cda} 3$

19. Whitmore RG, Stephen JH, Vernick C, Campbell PG, Yadla S, Ghobrial GM, Maltenfort MG, Ratliff JK (2014) ASA grade and Charlson Comorbidity Index of spinal surgery patients: correlation with complications and societal costs. Spine J 14:31-38. https ://doi.org/10.1016/j.spinee.2013.03.011

20. Veeravagu A, Li A, Swinney C, Tian L, Moraff A, Azad TD, Cheng I, Alamin T, Hu SS, Anderson RL, Shuer L, Desai A, Park J, Olshen RA, Ratliff JK (2017) Predicting complication risk in spine surgery: a prospective analysis of a novel risk assessment tool. J Neurosurg Spine 27:81-91. https://doi. org/10.3171/2016.12.spine16969 


\section{Affiliations}

Maximilian F. Kasparek ${ }^{1} \cdot$ Friedrich Boettner ${ }^{2} \cdot$ Anna Rienmueller $^{1} \cdot$ Michael Weber $^{3} \cdot$ Philipp T. Funovics $^{1}$. Petra Krepler ${ }^{1} \cdot$ Reinhard Windhager $^{1}$. Josef Grohs ${ }^{1}$

1 Department of Orthopaedics and Trauma Surgery, Vienna General Hospital, Medical University of Vienna, Waehringer Guertel 18-20, 1090 Vienna, Austria

2 Adult Reconstruction and Joint Replacement Division, Hospital for Special Surgery, 535 East 70th Street, New York, NY 10021, USA
3 Department of Biomedical Imaging and Image-Guided Therapy, Medical University of Vienna, Waehringer Guertel 18-20, 1090 Vienna, Austria 